\title{
Design and Development of Battery Operated Mango Harvester
}

\author{
K.B. Jhala*, R.D. Bandhiya and H. Thoriya \\ Department of Farm Machinery and Power Engineering, College of Agricultural Engineering \\ and Technology, Junagadh Agriculture University, Junagadh, Gujarat 362001, India \\ *Corresponding author
}

\section{A B S T R A C T}

Worldwide India ranks second in production of fruit. Traditional harvesting of mango fruits is either carried out by hand plucking or using traditional harvester (Vedo). In both

\section{Keywords}

Fruit picker, Mango harvester,

Harvesting device

Article Info

Accepted:

12 July 2018

Available Online:

10 August 2018 traditional harvesting and hand plucking methods, there are chances of liquid getting splashed over the body of operator and fruit may also get damaged which results in reduction in yield or return and traditional method is also time consuming. In addition, manual harvester requires more effort in operation. In order to overcome the problem and limitations of the manual harvesting method, a battery-operated harvesting device was designed and developed. Battery operated harvester consist of light weight pole, conveyor, $12 \mathrm{~V}$ DC battery, DC motor (high speed), GI blade, camera, display and switch. The main objective of battery operated mango harvester is to enhance timeliness of operation, keeping in view the comfort of an operator. A camera having 2 MP high resolutions with 7 inch display is mounted on device. Operator need not to look up continuously to the tree and there for ease of operation is observed in cutting with circular blade fitted to high speed motor. Efficiency of battery operated harvester is observed very high as compared to manual harvester, as it cuts around 350 fruits per hour.

\section{Introduction}

Mango (Mangifera indica L.) is one of the most important fruit in India and growing all over the world. Mango is considered to be one of the most preferred fruit of the world because of their attractive color, delicious taste and excellent nutritional properties. In India alone, there are around 283 varieties of mangoes, out of which only thirty are wellknown. Some important varieties namely; Kesar, Alphonso, Dasheri, Langra, Neelum,
Rajapuri, Pairi, Bombay green, Fazil, Totapuri, Chausa, Jamadar, Vanraj, Banglore, and Swarnrekhaetc. Mango fruit occupies a prominent place among all the fruits and is considered as the "King of Fruits". According to Apeda data, India cultivates mangoes in around 220 thousand hectares and the annual output is around 19 Million tons. The average productivity of 5.5 metric tons per hectare in India is comparatively low against $35-40$ metric tons per hectare realized in Israel (Balamohan et al., 2008). 
Harvesting is one of the most important operations in fruit production, handling and preservation cycle. People harvested fruits by hand until relatively recent time. Later, they learned knock fruits down with sticks or rocks shaking small trees and climbing on to trees with the aid of crude ladders to position themselves better for picking. Other existing methods of fruits harvesting are manual harvesting of fruits with use of mechanical aids, mechanical detachment of fruits by direct contact devices, vibratory mechanism for the harvesting of fruits etc. In Saurastra region of Gujarat state, mango harvesting is still carried out by hand picking and the traditional manual harvester (Vedo). Hand detachment is an effective means of removing fruits from the tree which may result in relatively low damage to the fruit.

The traditional manual harvester (Vedo) requires more time and energy and also has less capacity. In India harvesting of fruits is mostly done manually by means of a curved knife, blades attached to a hanging basket to the distant end of bamboo sticks (Devnani, 1980). These methods results high labor, high energy requirements, drudgery, and damage to fruits and branches etc. The damage and bruising are also serious problems. Fruits harvested with 8-10 $\mathrm{mm}$ long stalks look better on ripening as undesired spots on the skin caused by sap burn are prevented. Such fruits are less prone to stem-end rot and other storage diseases (Sapowadia et al., 2001).

Human comfort is the most important consideration in harvesting, which needs more effort and also difficult. To overcome this problem battery operated mango harvester is designed with a view to minimize the force of detaching the fruit and keeping ergonomics in mind for the comfort of an operator. Cutting force is by means of electric motor powered by DC battery. Also a collecting device is provided and a conveyor with a sack that work as device to divert the harvested fruits safely to a place near an operator.

\section{Materials and Methods}

The proposed mango fruit harvesting device was designed and fabricated in the workshop of the department of Farm Machinery and Power Engineering, College of Agricultural Engineering and Technology, Junagadh. Designing considerations for manually operated mango harvesters were make a device easy to operate, light in weight, minimize harvesting loss, and maximize harvesting efficiency along with the durability and reliability of device.

Designed mango harvester consist of the components like Ring, SS pole, Battery, Motor, Blade, Camera, Display, Display holder, Conveyor, Wire, and Switch to control (Figure 1).

\section{Ring}

A ring as in figure was made from $8 \mathrm{~mm}$ thick iron bar. It was designed and fabricated for supporting the motor meant for cutting the stalk of the fruit. The motor holder was placed such that the blade on the motor touches the fruit stalk perpendicularly and it made an angle of $45^{\circ}$ approximately with the horizontal line.

\section{SS Pole}

A successful mango harvester (Valdez, 1999) consists of a $6 \mathrm{~m}$ pole that could be adjusted depending on the height of the fruit to be harvested. The upper pole is $12 \mathrm{~mm}$ in diameter and $3 \mathrm{~m}$ in length while the lower pole is $19 \mathrm{~mm}$ in diameter and $3 \mathrm{~m}$ in length. So in this development, the pole is made of hollow stainless steel pipe of 11 feet length which has $24 \mathrm{~mm}$ inner diameter and $26 \mathrm{~mm}$ outer diameter. It acts as a foundation of 
different components of the harvester. Ring is attached on one end of the pole by means of nut and bolt. Looking to the strength, durability and long life, stainless steel pipe was selected. It is also more reliable and resistant to deformation.

\section{Battery}

Looking to the requirement of the display unit and the motor to be operated, the capacity of the battery was kept as $12 \mathrm{~V}$ and $7.5 \mathrm{~A}$ minimum. The weight of the battery was 1.5 $\mathrm{kg}$ and it provides a backup of about 3 hours.

\section{Motor}

High speed 12V D.C motor having a speed of $6000 \mathrm{rpm}$ was used. Motor was mounted on motor holder at upper end of the ring. Blade is mounted on the shaft of motor. Motor is controlled by a micro-switch suitably placed.

\section{Blade}

Three circular blades (GI) having 36, 40 and 45 teeth were tested. Finally $1 \mathrm{~mm}$ thickness with $84 \mathrm{~mm}$ diameter blade was used. Blade is welded on the motor shaft using gas welding technique.

\section{Camera}

A light weight camera having2MP resolution was used. It was mounted at the junction of SS pole and ring. So as to minimize the disturbance, size of camera was kept very small. The camera being fitted nearer to the cutting zone gives a clear vision of cutting area $\&$ the fruit condition operator can decide whether to harvest or not. Moreover operator can ensure the proper cutting of fruit without any damage during the operation.

\section{Display}

A display (Bluetooth and USB compatible 7inch) having 720-pixel visual clarity was used.
Display with display holder was mounted on operator's waist. Due to the display operator need not to look at top frequently. Camera and display were connected with each other. It displays the harvesting of the fruits at a time so that operator can ensure the condition and quality of fruit for proper harvesting.

\section{Display holder}

Display holder made from $8 \mathrm{~mm}$ thick iron rod having approximate length of $120 \mathrm{~cm}$. Display holder as the name suggest it holds display at convenient position. A pad is provided on the display holder so that the attachment and detachment of the display is easy.

\section{Conveyor}

Conveyor is made of plastic net. It is meant to convey fruit from ring to fruit bucket without any damage. Conveyor was light in weight and its length was conveniently kept as $5 \mathrm{~m}$.

\section{Wire}

$0.5 \mathrm{~mm}$ outer diameter aluminum wire was used to supply power from battery to camera, display and de motor.

\section{Switch}

Micro switch (push buttonsquare11 $\mathrm{mm} \times 11$ $\mathrm{mm}$ )was used to operate dc motor as and when required. A suitable stand for the switch is provided at a comfortable height on the pole and the switch is fixed on the stand.

\section{Results and Discussion}

The experimental testing was carried out and performance of the device was evaluated in the farm of the department of Farm machinery and power engineering of the college of Agricultural Engineering and Technology Junagadh Agricultural University, Junagadh. 
Table.1 Performance of harvesting unit time

\begin{tabular}{|c|c|c|c|}
\hline $\begin{array}{c}\text { Sr. } \\
\text { No. }\end{array}$ & $\begin{array}{c}\text { Time required } \\
\text { for harvesting }(\mathrm{sec} .)\end{array}$ & $\begin{array}{c}\text { No. of fruits } \\
\text { harvested }\end{array}$ & Fruits harvested per minute \\
\hline $\mathbf{1}$ & 240 & 20 & 5 \\
\hline $\mathbf{2}$ & 180 & 21 & 7 \\
\hline $\mathbf{3}$ & 210 & 21 & 6 \\
\hline $\mathbf{4}$ & 120 & 16 & 8 \\
\hline $\mathbf{5}$ & 300 & 20 & 4 \\
\hline $\mathbf{6}$ & 240 & 28 & 7 \\
\hline $\mathbf{7}$ & 180 & 15 & 5 \\
\hline $\mathbf{8}$ & 150 & 22 & 9 \\
\hline $\mathbf{9}$ & 270 & 15 & 3 \\
\hline $\mathbf{1 0}$ & 180 & 18 & 6 \\
\hline Avg. & & & 6 Fruits/min \\
\hline
\end{tabular}

Fig.1 Battery operated mango harvester

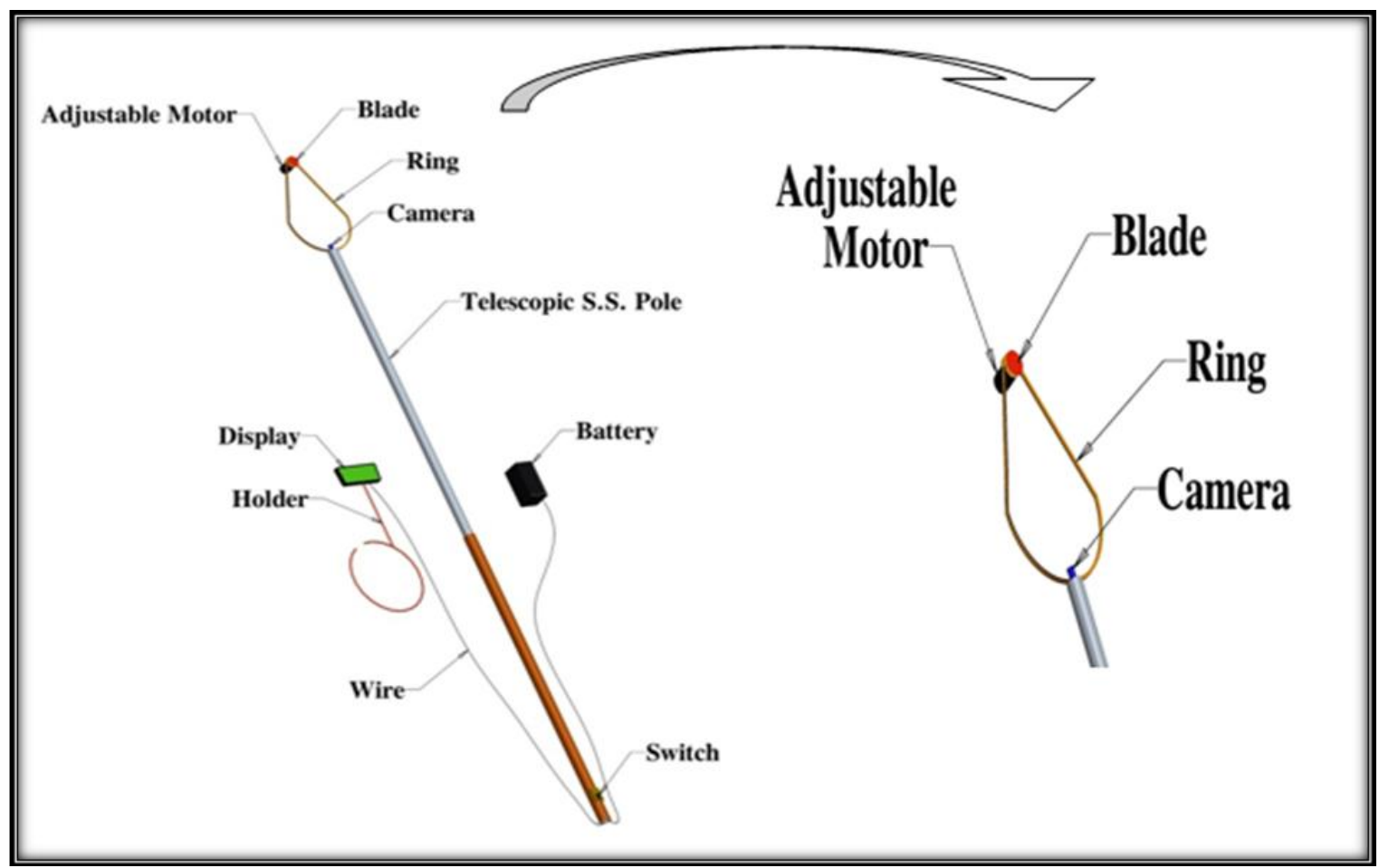

Designed device was tested on 10 trees and the results are as follows. The harvesting time and number of harvested fruits with harvesting efficiency are noted in Table 1.

Result reveled that, with the help of developed device fruits were harvested efficiently without damage at the rate of about 6(six) fruits per minute which seems favorable to the cutting device and ergonomically suitable. The results were found satisfactory as same obtained by electrical scissors harvesting of mango fruit to reduce the number of manual pickers needed and maximize picker productivity and reduce harvesting costs (Soliman et al., 2012). 
The major conclusions drawn from the experiment were;

In traditional harvesting, after harvesting 5 to 7 fruits the basket needs to be emptied for minimizing the weight on hand and therefore the total time of harvesting was higher, whereas developed harvester does not need that time and the fruits are safely conveyed to the ground while harvesting is going on.

The use of developed harvester is found to minimize harvesting losses and also the risk of splashing of liquid. It also has increased the overall efficiency of harvesting along with the harvesting capacity.

Developed device harvested the fruits efficiently without damage and that too ergonomically safe for long duration operation.

\section{Acknowledgement}

Junagadh Agricultural University, Junagadh and Department of Farm Machinery and Power Engineering staff members are gratefully acknowledged.

\section{References}

Balamohan, T. N., Mekala, P., Rajadurai, S., Priyadharshini, G., Prakash, K., Soorianathasundaram, K. and Kumar, N. 2008. Canopy management in mango. An unpublished M. Tech. thesis, Tamil Nadu Agricultural University, Coimbatore.

Devnani, R. S. 1980. Harvesting equipment developed in India. Technical bulletin no. CIAE/ 78 / 8, CIAE, Bhopal.

Sapowadia, B. D., Patel, H. N., Gupta, R. A. and Pund, S. R. 2001. Design and development of mango harvesting device. AMA.30(1): 31-34.

Soliman, A. H., El-Iraqi, M. E., Sharobeem, Y. and Awais, T. R. 2012. Development and Evaluation of Mechanical Picking Heads for Citrus fruits harvesting. AMA. 43(2): 50-58.

Valdez, J.A. 1999. Mango fruit harvester. Regional Research and Development Symposia, Philipine Council for Agricultural, Forestry and Natural Resources, Research and Development, Los Bonos, 15 Jul-11 Sep 1998.

\section{How to cite this article:}

Jhala, K.B., R.D. Bandhiya and Thoriya, H. 2018. Design and Development of Battery Operated Mango Harvester. Int.J.Curr.Microbiol.App.Sci. 7(08): 1998-2002.

doi: https://doi.org/10.20546/ijcmas.2018.708.230 